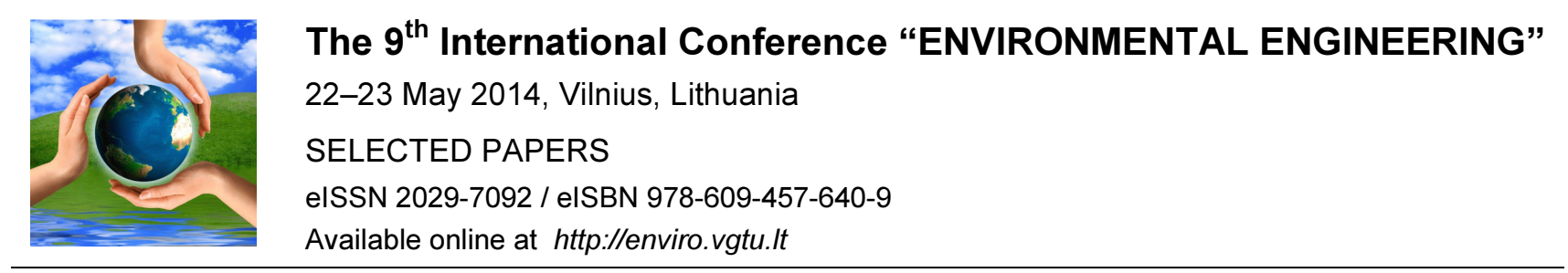

Section: Environmental protection

\title{
Investigation of collection efficiency of electrostatic precipitator for small heating appliances
}

\author{
Robertas Poškas, Arūnas Sirvydas, Povilas Poškas, Jurgis Jankauskas \\ Lithuanian Energy Institute, Breslaujos str. 3, Kaunas LT-44403, Lithuania
}

\begin{abstract}
In northern countries, biofuel is widely used to provide centralized heating and electricity production. In Lithuania, use of biofuel is also currently increasing: it is used not only in industrial areas but is also as a popular type of fuel for small scale household furnaces. Although carbon dioxide, released during combustion of biofuel, is not treated as a gas causing the greenhouse effect, the main disadvantage of this type of fuel in comparison to combustion of some gaseous or liquid fuels is rather high emissions of coarse, fine and ultrafine solid particles. Long term exposure to such types of particulate matters causes health problems. Electrostatic precipitation is a very reliable method to control particulate emissions from boilers, incinerators, and other industrial processes. However, its application for small scale heat production appliances is still limited.

The aim of this work is to evaluate the capability (efficiency) of a small scale electrostatic precipitator to capture solid particles emitted during incineration of wood pellets. Wood pellets were incinerated in an automatic boiler with the rated thermal output of $50 \mathrm{~kW}$. During investigations, distributions of solid particles were measured in the chimney using infrared particle sizer which is able to measure particles in the range from $0.4 \mu \mathrm{m}$ to $300 \mu \mathrm{m}$. Results showed that there are mainly solid particles in the flue gases with diameters from $0.4 \mu \mathrm{m}$ to $\sim 20 \mu \mathrm{m}$. Investigations were performed at different supply voltages to the discharge electrode of the electrostatic precipitator (ESP). This allowed determining collection of the particles by the ESP in case of different strength of the electrostatic field. In general, the total collection efficiency of $\sim 99 \%$ was achieved.
\end{abstract}

Keywords: electrostatic precipitator; small heating appliances; wood pellets; flue gasses.

\section{Introduction}

Biofuel has a considerable potential as a fuel source and a reasonable cost level in comparison to other types of fuel. It is widely used in many countries to provide centralized, medium and large-scale production of process heat for electricity production [1]. Biofuel (e.g. wood, straw, grains, etc.) is also a renewable energy source [2] making the least negative impact on the environment [3], therefore its use is increasing in newly built plants as well as in earlier built plants [4] in Lithuania.

The main type of biofuel used in Lithuania is wood, which consumption during the last decade was greatly increasing. The gross consumption in 2012 was about 998 thousands tonnes of oil equivalent [5]. Currently, it is also a popular type of fuel used in small scale household furnaces. However, one of the main disadvantages using biofuel in comparison with some other gaseous of liquid fuels are the emissions of coarse, fine and even ultra fine solid particles [6], which are especially increased in ambient air during the heating season.

Emissions studied from a $35 \mathrm{MW}$ circulating fluidized bed power plant [7] showed that in general particle emissions from biomass combustion (forest residue and willow) consist of two fractions - the aerosols (particles $<1 \mu \mathrm{m}$ ) and coarse particles (particles $>1 \mu \mathrm{m}$ ). It was obtained that size distribution of particles might be in two ranges - the first is between $\sim 0.03-0.5 \mu \mathrm{m}$ and the second is between $\sim 1-100 \mu \mathrm{m}$. The determined peak diameter of the particles in the first range for forest residue was about $0.1 \mu \mathrm{m}$ and for willow $-\sim 0.2 \mu \mathrm{m}$. Peak diameter in the second range for forest residue and willow

Corresponding author: Robertas Poškas. E-mail address: rposkas@mail.lei.lt

http://dx.doi.org/10.3846/enviro.2014.044

(C) 2014 The Authors. Published by VGTU Press. This is an open-access article distributed under the terms of the Creative Commons Attribution License, which permits unrestricted use, distribution, and reproduction in any medium, provided the original author and source are credited. 
was about $10 \mu \mathrm{m}$ and $\sim 5 \mu \mathrm{m}$, respectively. The maximum value of the particles' concentration in the first range was small only $\sim 4 \%$ for forest residue and approx. $20 \%$ for willow compared to the concentration in the second range.

Similar ranges were presented in the report [8], analyzing emissions of particles from large scale biomass combustion units (fixed bed combustion of wood chips, bark and waste wood). It was also shown that two ranges exist - the first was between $\sim 0.1-0.8 \mu \mathrm{m}$ and the second between $\sim 2-300 \mu \mathrm{m}$.

The effect from long term exposure to coarse $(>1 \mu \mathrm{m})$, fine $(0.1-1 \mu \mathrm{m})$ and ultra fine $(<0.1 \mu \mathrm{m})$ particulate matters $(\mathrm{PM})$ causes health problems, mainly pneumonia, cardio-vascular morbidity and premature mortality. This was confirmed by several studies [9-12].

In order to avoid negative effect on health, EU Council directive 1999/30/EC [13] defines the necessity to take certain measures to ensure that concentrations of PM10 (i. e. particles up to $10 \mu \mathrm{m}$ in diameter) in ambient air, assessed for different averaging periods ( $24 \mathrm{~h}$, annual) should not exceed the limiting values. Also, general strategies for decreasing concentrations of PM10 shall aim to reduce concentrations of PM2.5 (particles up to $2.5 \mu \mathrm{m}$ in diameter).Usually, before discharge to the atmosphere, flue gases in power plants are filtered (cleaned) in various types of filters such as multicyclones of fiber filters. However, such types of filters are not very effective in case of fine or ultrafine particulates, therefore for that purpose electrostatic precipitators are used [14]. The advantages of the electrostatic precipitators are low aerodynamic drag and high effectiveness [15].

From 1993 till now, the use of biofuel is increasing not only in industrial area but also in households and rural areas [4]. This means that generation of solid particles as well as gaseous emissions also increases due to small combustion appliances. Since environmental protection problems are becoming more relevant, the requirements for production of small combustion appliances (with a nominal heat output up to $500 \mathrm{~kW}$ ) are being coordinated by the LST EN303-5:2012 standard [16]. In general this standard is aiming to increase the efficiency of the boilers and to reduce emissions. It also indicates the limiting emission values of $\mathrm{SO}_{2}, \mathrm{NO}_{\mathrm{x}}, \mathrm{CO}$, organic gaseous carbon and solid particles depending on boiler class (in total there are 3 classes specified ( 3,4 and 5 ) - the higher the class, the stricter the emissions).

In order to reduce emissions from small scale boilers, there are special standards applied in some countries. In Finland, limiting emissions are based on the best available technology (BT-F). In Nordic countries, limiting emissions are based on the voluntary environmental protection standard "The Swan" (SW-N) [2].

Intra [17] indicates that reports on installation of pollution control devices to small-scale biomass-fired furnaces are rare. For small-scale applications, it is desirable to employ a simple, compact, and inexpensive solution to avoid air quality problems related to biomass combustion. Electrostatic precipitation is a very reliable method to control particulate emissions from boilers, incinerators, etc. It is therefore applied to small combustors as well. In the study [17], a simple, compact, and cost-effective electrostatic precipitator was designed and constructed for removal of particulate matter from biomass burning in small combustors. The device was installed and operated successfully on a biomass-fired furnace. The overall collection efficiency of the precipitator was experimentally evaluated as a mass loading ratio. It was found that over $70 \%$ overall collection efficiency can be achieved with a relatively simple design. For the "generation" of solid particles, a boiler with a thermal capacity of $100 \mathrm{~kW}$ was used.

In another study [6], it is indicated that in Sweden, the number of small bio-fuelled plants is increasing, and there is a need for cost effective means to precipitate the ultrafine particles formed. One of such techniques may be electrostatic precipitation. In their paper, the authors describe field tests of a low cost factory built electrostatic precipitator, including not only investigation of collection efficiency, but also measurement of charging effectiveness. The collection efficiency was determined to be between $30 \%$ and $40 \%$ in the $0.04-0.12 \mu \mathrm{m}$ range for a single filter, and between $55 \%$ and $65 \%$ for dual filters in the same size range. When a particle trap (loosely steel wool for a duct length of one diameter) was added, the resulting collection efficiencies in the particle size range between 0.04 and $0.12 \mu \mathrm{m}$ was between $65 \%$ and $85 \%$.

Schmatloch and Rausch [18] presented the results from efforts to improve small heating appliances when burning solid fuel. For application in small heating systems, a compact and inexpensive solution that still offers a significant reduction of particle emissions is required. A specific design of electrostatic precipitator was presented and its collection efficiency and electrical characteristics were evaluated. Different geometries and electrode set-ups have been considered with the aim of developing a system that can also be retrofitted to existing installations. It was determined that the investigated precipitator resulted in collection efficiencies of more than $80 \%$. By improving the shape of the electrode, a collection efficiency of about $90 \%$ was achieved. This reduction of particle emissions was much higher than what is possible by further improvements of combustion quality. It was shown that even in the critical size range of about $0.1 \mu \mathrm{m}$, high collection efficiency can be achieved.

In the present study the investigations of specific electrostatic precipitator intended for small scale heating appliances is presented and its efficiency is evaluated.

\section{Experimental methods}

\subsection{Experimental setup}

Experimental setup used to evaluate the characteristics of the electrostatic precipitator (ESP) is presented in Figure 1. Flue gases were generated by incinerating fuel in a boiler. A boiler is designed to meet class 3 requirements according to EN3035:2012 [16]. It is an automatic device with a rated power of $50 \mathrm{~kW}$ and can be used for incineration of pellets, wood, 
pea-coal and cereals. The fuel supply and air supply for combustion are regulated basing on the set boiler power. During experiments, only wood pellets were incinerated. Flue gas temperature exhausted from the boiler was about $150{ }^{\circ} \mathrm{C}$ and the chimney draft $\sim 25 \mathrm{~Pa}$ (the draft value was automatically kept by the flue gas exhauster). Such draft gives a flue gas velocity of approx. $1.9 \mathrm{~m} / \mathrm{s}$ in the flue gas pipe of $180 \mathrm{~mm}$ diameter (flow rate $\sim 177 \mathrm{~m}^{3} / \mathrm{h}$ ). The total height of the insulated flue gas pipe was about $15 \mathrm{~m}$. From the boiler, flue gases enter the ESP, where the solid particles are captured and then clean flue gases are exhausted to outside. The ESP (see Fig. 2) used in the experiments was designed at Lithuanian energy institute. Its frame was made from carbon steel angle bars. The inlet to the ESP was made in the upper part and the outlet was positioned in the lower part. Inside the frame, two parallel stainless steel pipes with a diameter of $120 \mathrm{~mm}$ (each) and a length of $1000 \mathrm{~mm}$ were installed between two holding planes. A single nichrome wire of $0.2 \mathrm{~mm}$ was stretched between the special electrodes inside the centres of each stainless steel pipe. The distance between electrodes was about $160 \mathrm{~mm}$. The electrodes were connected to Glassman Series FR high voltage power supply unit with adjustable output voltage in the range between 0 and $30 \mathrm{kV}$.

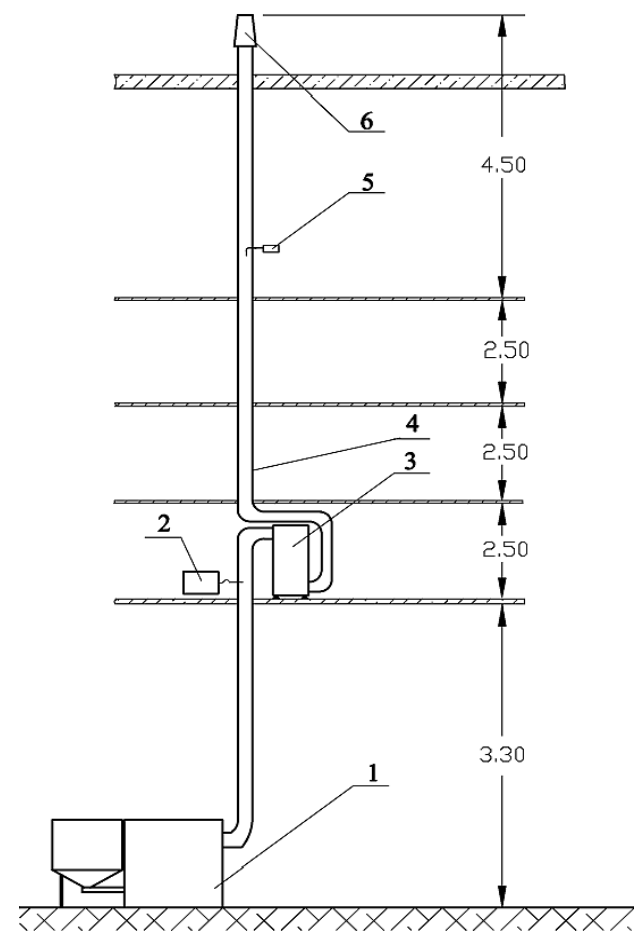

Fig. 1. Experimental setup (not to scale):

1 - boiler; 2 - flue gas analyser; 3 - electrostatic precipitator;

4 - flue gas pipe (chimney); 5 - infrared particle sizer; 6 - flue gas exhauster

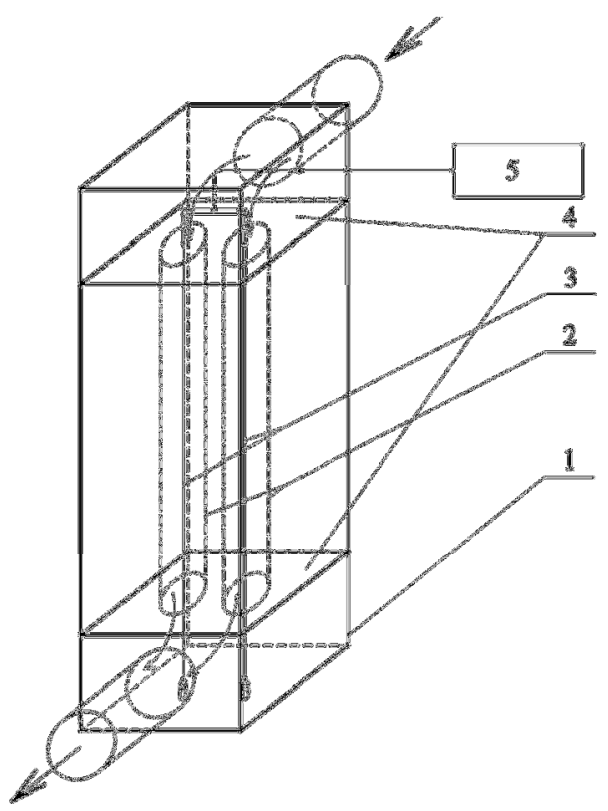

Fig. 2. Electrostatic precipitator (not to scale): 
The current-voltage characteristic (high voltage supply unit used in experiments has a feature enabling it to measure the current in the electrode depending on supplied voltage) of this type of electrode is shown in Fig. 3. From the figure (see Fig. 3, curve 1) it is evident that current was registered starting from the voltage of $\sim 6 \mathrm{kV}$.

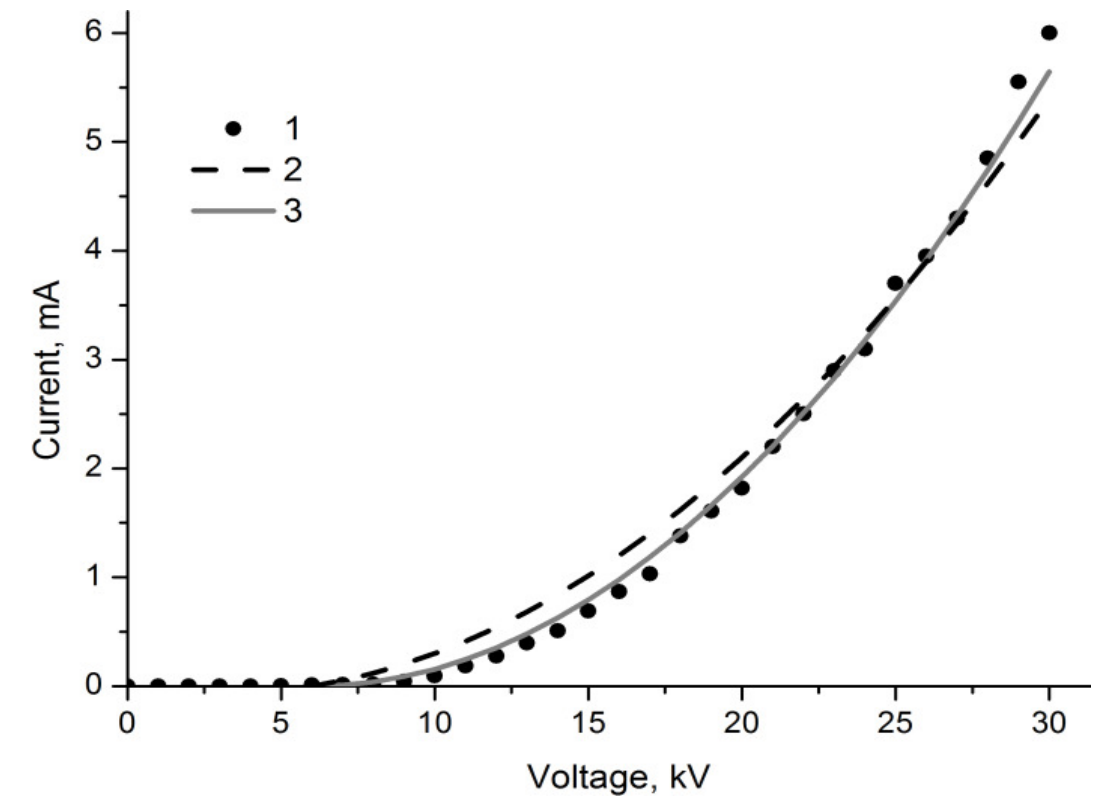

Fig. 3. Current-voltage characteristic of the ESP electrode:

1 - experimental data; 2 - based on Townsend equation; 3 - based on modified Townsend equation

This means that from this point the electrostatic discharge, which ionizes the flue gas around the discharge electrode (i.e. creates corona), occurs. Although electrical corona is a rather complex phenomenon, a simple empirical relationship is used for the current-voltage characteristics for concentric wire and cylinder geometry. It is the Townsend relation [19]:

$$
I=k \cdot U\left(U-U_{0}\right) \text {, }
$$

where: $k$ and $U_{0}$ are experimentally determined constants, $I$ is the current (A) and $U$ is the voltage (V).

However, in many cases so called modified Townsend relation is used to describe current-voltage characteristic of the electrode:

$$
I=k \cdot\left(U-U_{0}\right)^{2} .
$$

In Fig. 3, it is shown that modified Townsend relation (Fig. 3, curve 3) gives better agreement with the experimental data in comparison with Townsend relation (Fig. 3, curve 2). This was also indicated in other study [18].

Constants $k$ and $U_{0}$ for modified Townsend relation were obtained by fitting eqn. (2). The constant $k$ was found to be $9.8 \cdot 10^{-3} \mathrm{~A} / \mathrm{V}^{2}$ and $U_{0}$ (which is also called as the voltage of the corona discharge) is $6 \mathrm{kV}$.

Constants $k$ and $U_{0}$ for Townsend relation (obtained by fitting eqn. (1)) were the following: $k=7.5 \cdot 10^{-3} \mathrm{~A} / \mathrm{V}^{2}$ and $U_{0}=6 \mathrm{kV}$.

\subsection{Measuring techniques}

An infrared particle sizer (IPS) was installed in the chimney segment between the electrostatic precipitator and flue gas exhauster (Fig. 1, pos. 5). IPS is an instrument for direct measurements of total dust concentration and concentration of dust fractions in flue gas channels. It is composed of a measuring head and an electronic computer-controlled measurement unit. Operation of IPS is based on the principle of light scattering. Infrared light is scattered by particles moving through the measurement zone. Each particle moving through the measurement zone generates an electric pulse proportional to the diameter of the spherical particle. In case of non-spherical particles, the pulse amplitude depends on how the particle is oriented in the measurement zone. So, this device ensures only 1D measurements and it may be used for measurements of particles in the range from 0.4 to $300 \mu \mathrm{m}$ (this range is divided into 4 subranges). IPS also measures flue gas temperature, flue gas velocity and flow rate. The software provided for IPS management automatically calculates particle concentrations in cubic meter of flue gases.

To ensure that stream of flue gases flowing into the intake nozzle of the IPS measuring head is not disturbed (in order to obtain a representative sample), the suction of the gases was isokinetic. The measuring head is also equipped with special holder for the filter which can be used for the determination of concentration of solid particles by gravimetric method.

The gaseous emissions from the boiler and excess air values during the experiments were measured using flue gas analyser IMR2000. 


\section{Results and discussions}

\subsection{Emissions from the boiler}

Gaseous emissions from the boiler were measured in the position as indicated in Fig. 1 (see pos. 2). The measured and averaged emissions are presented in Table 1. For comparison purposes, the same table presents the limiting emissions indicated in EN303-5:2012 standard [16], emissions based on the best available technology (BT-F) and on the voluntary environmental protection standard "The Swan" (SW-N). EN303-5:2012, BT-F and SW-N also provide limiting emission values for organic gaseous carbon (OGC). During the experiments OGC was not measured therefore it is not in the table.

Table 1. Emissions from the boiler. Measured emissions are presented for the reference value of $\mathrm{O}_{2}-10 \%$

\begin{tabular}{lllllll}
\hline & $\begin{array}{l}\text { CO2 } \\
\text { \% }\end{array}$ & CO & NO & NO2 & SO2 & PM \\
& 10.5 & 245 & 103 & 0 & mg/Nm3 & mg/Nm3 \\
\hline Measured & - & 3000 & - & - & - & 12.8 \\
\hline EN303-20121 & - & - & 1252 & - & 375 & - \\
BT-F3 & - & 1000 & - & - & - & 70 \\
SW-N3 & & & & &
\end{tabular}

Table 1 shows that average measured $\mathrm{CO}_{2}$ value was $10.5 \% . \mathrm{CO}_{2}$ is a rather important parameter which allows judging the operatibility of the boiler and it is also used to calculate $\mathrm{O}_{2}$ content in the flue gases. Maximum $\mathrm{CO}_{2}$ value for wood fuel combustion without excess air supply should be about $20 \%$ [2]. Producer of the boiler recommends excess air value to be in the range $2.0-2.4$. During experiments, excess average air value was about 2.25 and $\mathrm{O}_{2}$ content $\sim 12.38 \%$.

Measured carbon monoxide value was more than ten times lower in comparison to the limiting value presented in EN303-5:2012 [16], and about four times lower compared to the value provided in SW-N. Quantity of Nitrogen oxide $\left(\mathrm{NO}_{\mathrm{x}}=\mathrm{NO}+\mathrm{NO}_{2}\right)$ was close but not exceeding the limiting value indicated in $\mathrm{BT}-\mathrm{F}$. Some small quantity of $\mathrm{SO}_{2}$ was also determined. However, in all cases it was very far from the limit.

Concentration of solid particles (PM) was measured using IPS (see Fig. 1, pos. 5), and the result presented in Table 1 is based on gravimetric method. It was obtained that concentration of the solid particles is rather low $-\sim 13 \mathrm{mg} / \mathrm{Nm}^{3}$, while the limiting values are much higher (cf. Table 1). Concentration of the solid particles in case of wood pellets combustion determined by Vonžodas [4] was $21.5 \mathrm{mg} / \mathrm{Nm}^{3}$.

\subsection{Collection efficiency of electrostatic precipitator}

When no voltage is applied, there are solid particles in flue gases mainly with the diameters from 0.4 to $\sim 20 \mu \mathrm{m}$. The highest quantity of the particles in the distribution was with the diameter of about $4 \mu \mathrm{m}$.

The obtained relative distribution of particles concentration dependence on supplied voltage is presented in Fig. 4. Initially, increase of voltage till $2 \mathrm{kV}$ resulted in concentration decrease by $\sim 12 \%$. At $4 \mathrm{kV}$ the concentration of particles was already decreased by $25 \%$ (almost linear dependency). Then, at corona discharge $(6 \mathrm{kV})$, the sharp decrease of particles concentration by $85 \%$ was observed. Further, increase of voltage till $8 \mathrm{kV}$ gave only slight decrease of concentration.

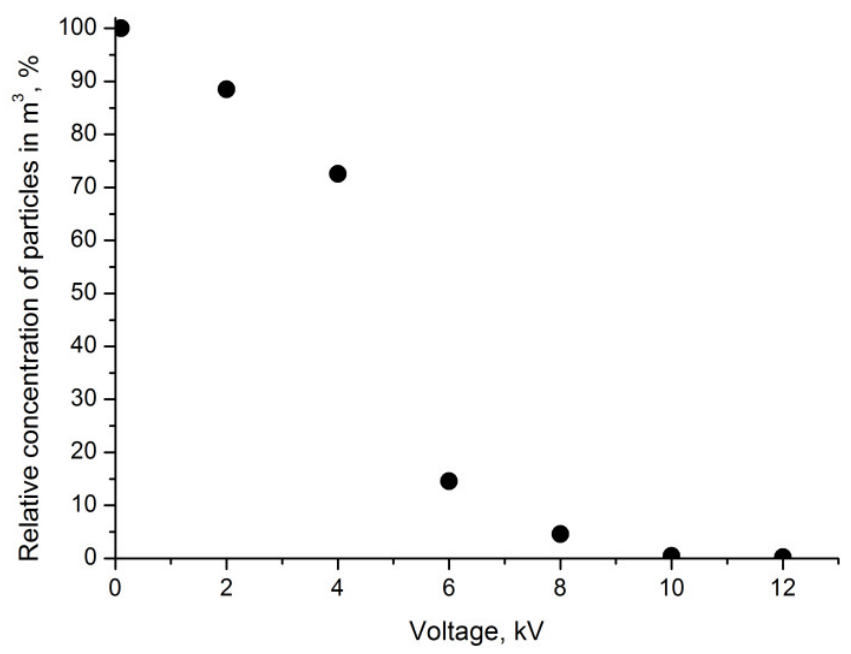

Fig. 4. Dependence of relative concentration of particles on supplied voltage to ESP 
When the voltage was increased till $10 \mathrm{kV}$ or even $12 \mathrm{kV}$, the concentration of particles was already very small. Thus in general, the use of ESP allowed to decrease the concentration of solid particles for about $99 \%$.

Variation of total collection efficiency of particles with power of the ESP is presented in Fig. 5. First of all the collection efficiency of the ESP $\left(E_{i}\right)$ was calculated based on the following equation [20]:

$$
E_{i}=\left(1-\frac{N_{f_{i}}}{N_{i}}\right) \cdot 100
$$

where: $N_{f i}$ is the quantity of particles with the diameter $i$ obtained using ESP; $N_{i}$ is the quantity of particles with the diameter $i$ obtained without ESP. Then, the total collection efficiency of the ESP was calculated as the average value of collection efficiency $E_{i}[20]$. The power of the ESP $(P)$ was obtained by multiplying current $(I)$ and voltage $(U)$ supplied to the discharge electrode of the ESP.

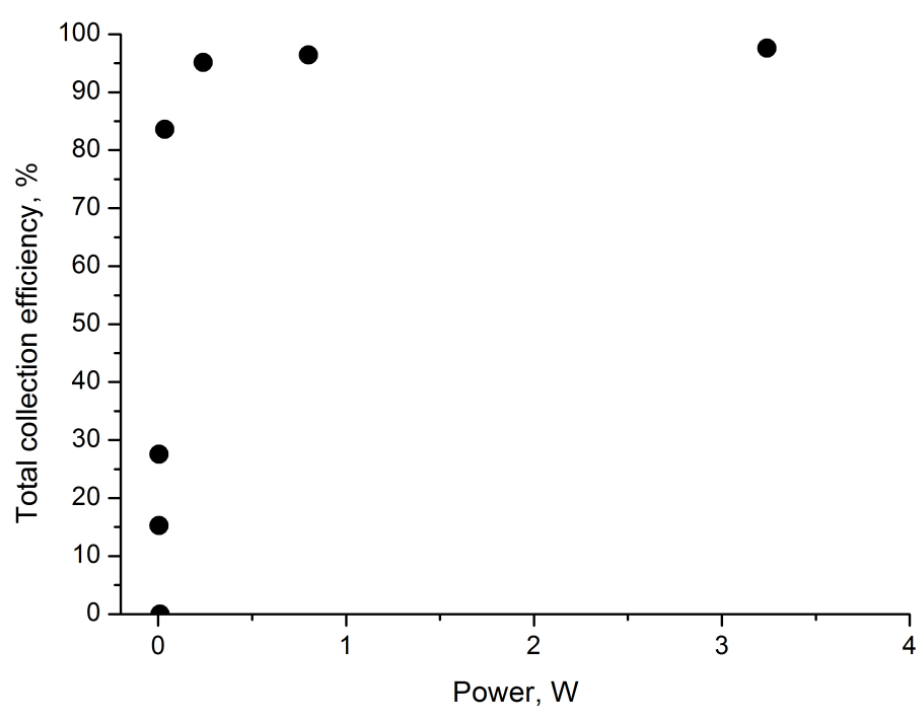

Fig. 5. Variation of total collection efficiency of particles with power of the ESP

Until corona discharge, although power is $\sim 0 \mathrm{~W}$ (i. e. current is so small that it is practically non-measurable), the total collection efficiency of the ESP increases slightly and reaches approx. $27 \%$. At the corona discharge $(6 \mathrm{kV})$ power is also almost $0 \mathrm{~W}$, but total collection efficiency is $\sim 85 \%$. Slight increase in power to $0.25 \mathrm{~W}$ resulted in collection efficiency of $\sim 95 \%$. Further increase in power results only in small total collection efficiency increase. When the power was $3.25 \mathrm{~W}$, the calculated total collection efficiency was $\sim 99 \%$. The variation of the total collection efficiency with power of the ESP is similar to this characteristic obtained by Schmatloch and Rausch [18].

\section{Conclusions}

After experimental investigations of the electrostatic precipitator for small-scale heating appliances, the following conclusions can be made:

- Solid particles mainly with diameters from $0.4 \mu \mathrm{m}$ to $\sim 20 \mu \mathrm{m}$ were determined in the flue gases, while the peak diameter was $\sim 4 \mu \mathrm{m}$.

- Until corona discharge (till $6 \mathrm{kV}$ ) with increase of the voltage, the total collection efficiency reaches about $25 \%$. A sharp increase in total collection efficiency (till $\sim 85 \%$ ) is observed at corona discharge (at $6 \mathrm{kV})$.

- Even low power of the ESP $(0.25 \mathrm{~W})$ allowed to achieve total collection efficiency of solid particles equal to $\sim 95 \%$. Further increase of power resulted only in slight increase of collection efficiency and at the $3.25 \mathrm{~W}$, total collection efficiency of $\sim 99 \%$ was achieved. Further, increase of power did not give any marked results.

\section{References}

[1] Demibras, A. 2007. Combustion Systems for Biomass Fuel, Energy Sources 29(4): 303-312. http://dx.doi.org/10.1080/009083190948667

[2] Vares, V. 2007. Biokuro naudotojo žinynas [Manual for biofuel users]. Tallinn University of Technology. 167 p.

[3] Gimbutaite, I.; Venckus, Z. 2008. Air pollution burning different kinds of wood in small power boilers, Journal of Environmental Engineering and Landscape Management 16(2): 97-103. http://dx.doi.org/10.3846/1648-6897.2008.16.97-103

[4] Vonžodas, T.; Pedišius N.; Valantinavičius, M. 2013. Investigation of performance parameters of low capacity water boilers burning biofuel, Power engineering 59(2): 93-103.

[5] Kuro ir energijos balansas [Energy balance]. 2013. Lietuvos statistikos departamentas. 54 p.

[6] Pettersson, J.; Strand, M.; Lin, L. 2011. Charging- and removal efficiency of an ESP in a $250 \mathrm{~kW}$ biomass boiler in Proc. of the XII International Conference on Electrostatic Precipitation, ICESP Nürnberg. 
[7] Maenhaut, W.; Fernández-Jiménez, M.-T.; Lind, T.; Kauppinen, E.I.; Valmari T.; Sfiris, G.; Nilsson, K. 1999. In-stack particle size and composition transformations during circulating fluidized bed combustion of willow and forest residue, Nuclear Instruments and Methods in Physics Research Section B: Beam Interactions with Materials and Atoms 150(1-4): 417-421. http://dx.doi.org/10.1016/S0168-583X(98)01068-4

[8] Aerosols in fixed-bed biomass combustion - formation, growth, chemical composition, deposition, precipitation and separation from flue gas. Final report. 2003. Graz University of Technology. 12 p.

[9] Zelikoff, J. T.; Chen, L. C.; Cohen, M. D.; Fang, K.; Gordon, T. Li, Y.; Nadziejko, C.; Schlesinger, R.B. 2003. Effects of inhaled ambient particulate matter on pulmonary antimicrobial immune defense, Inhallation Toxicology 15(2):131-150. http://dx.doi.org/10.1080/08958370304478

[10] de Hartog, J.J.; Hoek, G; Peters, A.; Timonen, K.L.; Ibald-Mulli, A.; Brunekreef, B.; Heinrich, J.; Tiittanen, P.; van Wijnen, J.H.; Kreyling, W.; Kulmala, M.; Pekkanen, J. 2003. Effects of fine and ultrafine particles on cardiorespiratory symptoms in elderly subjects with coronary heart disease: the ULTRA study, American Journal of Epidemiology 157(7): 613-623. http://dx.doi.org/10.1093/aje/kwg021

[11] Pekkanen, J.; Peters, A.; Hoek, G.; Tiittanen, P.; Brunekreef, B.; de Hartog, J.; Heinrich, J.; Ibald-Mulli, A.; Kreyling, W.G.; Lanki, T.; Timonen, K.L.; Vanninen, E. 2002. Particulate air pollution and risk of ST-segment depression during repeated submaximal exercise tests among subjects with coronary heart disease - The expo-sure and risk assessment for fine and ultrafine particles in ambient air (ULTRA) study, Circulation 106(8): 933938. http://dx.doi.org/10.1161/01.CIR.0000027561.41736.3C

[12] Brunekreef, B.; Holgate, S.T. 2002. Air pollution and health, Lancet 360(9341): 1233-1242. http://dx.doi.org/10.1016/S0140-6736(02)11274-8

[13] COUNCIL DIRECTIVE 1999/30/EC of 22 April 1999 relating to limit values for sulphur dioxide, nitrogen dioxide and oxides of nitrogen, particulate matter and lead in ambient air. $20 \mathrm{p}$.

[14] Parker, K. L. 1997. Applied electrostatic precipitation. London: Chapman \& hall.

[15] Varonos, A. A.; Anagnostopoulos, J. S.; Bergeles, G. C. 2002. Prediction of the cleaning efficiency of an electrostatic precipitator, Journal of Electrostatics 55(2): 111-133. http://dx.doi.org/10.1016/S0304-3886(01)00187-5

[16] Heating boilers - Part 5: Heating boilers for solid fuels, manually and automatically stoked, nominal heat output of up to 500 kW - Terminology, requirements, testing and marking, LST EN303-5:2012. $81 \mathrm{p}$.

[17] Intra, P.; Limueadphai, P.; Tippayawong, P. 2010. Particulate emission reduction from biomass burning in small combustion systems with a multiple tubular electrostatic precipitator, Particulate Science and Technology 28(6): 547-565. http://dx.doi.org/10.1080/02726351003758444

[18] Schmatloch, V.; Rausch, S. 2005. Design and characterisation of an electrostatic precipitator for small heating appliances, Journal of Electrostatics 63(2): 85-100. http://dx.doi.org/10.1016/j.elstat.2004.08.001

[19] Leal Ferreira, G. F.; Oliveira, O. N.; Giacometti, J. A. 1986. Point-to-plane corona: Current-voltage characteristics for positive and negative polarity with evidence of an electronic component, Journal of Applied Physics 59(9): 3045-3049. http://dx.doi.org/10.1063/1.336926

[20] Mussati, D. C. 2002. EPA air pollution control cost manual (Sixth Edition). Research Triangle Park. 752 p. 